DOI: http://dx.doi.org/10.1590/S0104-64972015002310

\title{
Variation of amphipod assemblage along the Sargassum stenophyllum (Phaeophyta, Fucales) thallus
}

Glauco Barreto de Oliveira Machado, Aline Binato Neufeld, Simone Aparecida Dena, Silvana Gomes Leite Siqueira and Fosca Pedini Pereira Leite

(GBOM, SAD) Pós-Graduação em Ecologia, Universidade Estadual de Campinas (UNICAMP). Avenida Bertrand Russell. 13083-970 Campinas, São Paulo, Brazil. E-mail: gbomachado@gmail.com.

(ABN) Pós-graduação em Biologia Animal, Universidade Estadual de Campinas (UNICAMP). 13083970 Campinas, São Paulo, Brazil.

(SGLS) Departamento de Invertebrados, Setor de Carcinologia, Museu Nacional, Universidade Federal do Rio de Janeiro (UFRJ). 20940-040 Rio de Janeiro, Rio de Janeiro, Brazil.

(FPPL) Departamento de Biologia Animal, Instituto de Biologia, Universidade Estadual de Campinas (UNICAMP). 13083-970 Campinas, São Paulo, Brazil.

\begin{abstract}
The spatial distribution of fauna associated to marine macroalgae has mostly been investigated considering a horizontal plane. However, the macroalgal substrates can present a three-dimensional structure. In this sense, investigating how the associated fauna varies throughout a vertical plane can contribute to understanding the distribution of these organisms. The brown macroalga Sargassum presents a vertical stratification along its thallus and harbors an amphipod fauna with a variety of feeding habits. In this work, we tested if the amphipod assemblage varies along different portions of the Sargassum thallus. We collected whole Sargassum stenophyllum thalli, as well as isolated basal and distal portions, from a rocky shore located on the north coast of Sáo Paulo, in southeastern Brazil. The composition of amphipod families varied according to the Sargassum portion and the families Corophiidae, Caprellidae and Hyalidae accounted for most of the differences. Moreover, the basal portion of Sargassum had a higher diversity of amphipod families than the distal one, which may be related to differences regarding habitat complexity (herein, measured as algal biomass) between these portions. Detritivores (such as Corophiidae) were more associated to the basal portion and herbivores to the distal portion (Hyalidae) or along the whole Sargassum thallus (Ampithoidae). The variation of amphipod assemblage along Sargassum thallus seems to result from the interaction between the fauna natural history and the differences in conditions and physical structure along the algal thallus. In this sense, the vertical stratification of Sargassum can add another source of variation to the spatial distribution of associated fauna.
\end{abstract}

Key words: Spatial distribution, Macroalgae, Vertical stratification, Associated fauna.

\section{INTRODUCTION}

Studies concerning species distribution involve the description of patterns and their underlying processes. Describing the spatial distribution of species contributes to understanding ecological processes (e.g. interactions between organisms or with their environment) in a scale-dependent context (Wiens, 1989). In benthic environments, biological substrates provide habitat for other organisms and, as a result, they can have an important role on the composition of benthic communities (Coull and Wells, 1983; Castilla et al., 2004; Koivisto and Westerbom, 2010). The spatial distribution of the fauna associated to macroalgae has been reported mainly considering 
a horizontal plane (Kelaher et al., 2001; Tanaka and Leite, 2003). However, the macroalgal substrate can present a three-dimensional structure (Christie et al., 2007; Hirst, 2007). In this sense, exploring the composition of associated fauna in a vertical plane can contribute to understand the distribution of these organisms (Hirst, 2007).

The variation throughout the physical structure of algal substrates can result in a variety of microhabitats used by different species (Rossi et al., 2000; Fraschetti et al., 2006; Christie et al., 2007; Hirst, 2007). As an example, in kelp forests of Laminaria hyperborea (Gunn.) Foslie, 1884 a straight thallus algae, a vertical stratification has been found, which is represented by the differences regarding conditions (e.g. currents, sediment accumulation) and structures (lamina, holdfast and stipes) along this substrate (Eckman et al., 1989; Christie et al., 2007). As a result, such vertical stratification can affect the distribution of associated fauna (Christie et al., 2007; Hirst, 2007). In this sense, the differences between parts from the same biological substrate can add another source of variation to the spatial distribution of the associated fauna (Fraschetti et al., 2006).

On rocky shores of tropical and subtropical systems, Sargassum species compose an important fraction of the algae community (Eston et al., 1986; Paula, 1988). The Sargassum thallus contains a holdfast, a stipe, lateral branches and leaflets (Joly, 1967). Throughout the Sargassum thallus, conditions and physical structure can change, resulting in a vertical stratification. The holdfast, at its basal portion, allows the fixation of sessile organisms (e.g. sponges) that can function as a second biological substrate for mobile fauna (Leite et al., 2007). In addition, the amount of branches, which can shelter the fauna, is higher at the basal portion than the distal portion. Finally, the basal portion seems to be more protected from the action of waves, as suggested for other straight stem algae species (Fraschetti et al., 2006; Christie et al., 2007).

Sargassum provides shelter for a diversity of small invertebrates. Among its associated fauna, the amphipods present high abundance and species richness (Tanaka and Leite, 2003; Jacobucci et al., 2009), making them especially sensitive to changes in the spatial physical structure of the substrates. The amphipod assemblage associated to Sargassum presents distinct behavior and feeding habits (herbivores, predators and detritivores) (Barnard and Karaman, 1991; Guerra-García et al., 2014) that can promote changes in the species community regarding their use of microhabitats. In this study, we tested if the amphipod assemblage varies along different portions of the Sargassum thallus.

\section{Material AND Methods}

The study was conducted at Cigarras Beach, in the State of São Paulo, southeastern Brazil (S $\left.23^{\circ} 43^{\prime} 42.78^{\prime \prime W} 45^{\circ} 23^{\prime} 52.43^{\prime \prime}\right)$. In this area, the northern rocky shore is mainly composed of large boulders, which are predominantly dominated by Sargassum stenophyllum Martius, 1828 in the subtidal zone. The Sargassum fronds have approximately $30 \mathrm{~cm}$ of height and compose dense patches. We performed our sampling in the spring (October 2013), when most of the amphipods associated to Sargassum occur (Tanaka and Leite, 2003; Jacobucci et al., 2009).

To evaluate the association between the amphipod composition and each Sargassum portion, we randomly collected submerged samples $(0.5-1.0 \mathrm{~m}$ deep) from the basal and distal portions of the Sargassum thallus. For each portion of the thallus, we collected six replicates. We collected the samples underwater and stored them in voile bags of mesh size $0.2 \mathrm{~mm}$ for the fauna contention. For the distal portion, approximately half the length of the thallus, corresponding to the top portion, was involved in a bag. To assure sampling independence, the other half was discarded. Similarly, for the basal portions, the holdfasts were involved in bags before detachment from the rocks, and the distal portions were discarded. For the description of the amphipod fauna associated to $S$. stenophyllum, we took the whole thallus as samples $(n=6)$.

At the laboratory, the samples were frozen and then washed with fresh water to remove the fauna. These organisms were preserved in alcohol $70 \%$ and the amphipods were identified to the family level. We identified up to the families because the feeding habits are usually shared at this level, including the amphipod species commonly found in Sargassum in the studied region (Barnard and Karaman, 1991; Guerra-García et al., 2014). The macroalgae were dried at $70{ }^{\circ} \mathrm{C}$ for 24 hours and weighed to estimate the density of amphipods. The dry weight of Sargassum (biomass) was used 
as a measure of habitat complexity of each portion (McCoy and Bell, 1991). Moreover, from the amphipod density, we calculated the diversity of amphipod families for each portion using the Shannon-Wiener index.

The family composition for distal and basal portion of Sargassum was compared using a PERMANOVA approach (Anderson, 2001). In order to balance the contribution of frequent and rare groups (Anderson, 2001), the amphipod density was $\log$-transformed $(\log (\mathrm{X}+1))$, and then it was used to build a similarity matrix using the Bray-Curtis distance. This matrix was tested with a PERMANOVA with 9999 permutations. Based on the same matrix, we performed a PERMDISP (9999 permutations) in order to check the homogeneity of multivariate dispersions. NonMetric Multidimensional Scaling (nMDS) ordination was used to visually compare the basal and distal portions. To verify the families that most contributed to the dissimilarities between the Sargassum portions, we performed a SIMPER analysis. Moreover, we classified families according to their predominant feeding habits (herbivores, detritivores and predators) (Barnard and Karaman, 1991; Guerra-García et al., 2014). Finally, to compare amphipod diversity and Sargassum biomass between basal and distal portions, we used Student's $t$ test for independent samples.

\section{RESUlTS}

We collected 5237 amphipods associated to Sargassum stenophyllum, representing 11 amphipod families (Tab. 1). Among these families Hyalidae, Caprellidae, Corophiidae, Maeridae, Ampithoidae and Amphilochidae were the most abundant. The portion of the Sargassum thallus was determinant for the composition of amphipod families (PERMANOVA, $F_{(1,10)}=3.480, P=0.021$ ). This result is supported by the nMDS ordination (Fig. $1)$. We did not observe differences in variability among groups (PERMDISP, $F_{(1,10)}=0.077, P=$ $0.80)$. The families with most contribution to the dissimilarities between the portions were Corophiidae (24.54\%), Caprellidae (20.34\%) and Hyalidae (18.53\%) (SIMPER). The family Corophiidae was more abundant in the basal portion, while Caprellidae and Hyalidae were more abundant in the distal portion (Tab. 1).
The basal portion of Sargassum had a higher diversity $\left(\mathrm{H}^{\prime}\right)$ of amphipod families $(1.02 \pm 0.30)$ than the distal one $(0.56 \pm 0.14)$ (Student's $t$ test; $t$ $=3.35, \mathrm{df}=10, P=0.012)$. Six families were found in the distal portion, and the families Hyalidae and Caprellidae exhibited the higher densities. For the basal portion, Hyalidae, Caprellidae and Corophiidae had the largest densities among the eleven represented families. All families found in the basal or the distal portions were also found in the whole thallus samples, except Leucothoidae that was present in only one basal sample. Regarding the feeding habits, the detritivores were predominant in the base and herbivores in the distal portion (Tab. 1). We could not find consistent information about the feeding habits of Eusiridae. Finally, the basal portion of Sargassum had a higher biomass $(6.75 \pm 2.71 \mathrm{~g})$ than the distal one $(2.90 \pm 1.57 \mathrm{~g})$ (Student's $t$ test; $t=$ $3.01, \mathrm{df}=10, P=0.017)$.

\section{Discussion}

Our results provide evidence that the composition of amphipods varies throughout the Sargassum thallus and this pattern may be related to the feeding habits of these animals. Despite the limitations of this work concerning time and spatial sampling, we are confident that the results allow a consistent discussion since the families of amphipods found here are frequently associated to Sargassum in this region (Tanaka and Leite, 2003; Jacobucci et al., 2009). Moreover, considering these amphipod families have a wide distribution (Barnard and Karaman, 1991), we point out the patterns found in our study may be observed in other areas with straight thallus algae.

The composition of the algae-associated fauna may be related to habitat complexity. The algal structural complexity can influence factors related to the fauna occurrence, such as water flow (Dean and Connell, 1987), space for establishment (Hacker and Steneck, 1990) and protection from predation (Zamzow et al., 2010). A single alga can present portions with differences regarding physical structures, affecting the composition of the associated fauna (Fraschetti et al., 2006; Christie et al., 2007). The basal portion of Sargassum has more branches and higher structural complexity (herein, measured as biomass) than the distal portion, offering more 
Table 1. Mean density (ind/g of dry algae) ( \pm standard error) of the amphipod families associated to different portions of the Sargassum stenophyllum thallus. $\mathrm{H}=$ herbivore; $\mathrm{D}=$ detritivore; $\mathrm{P}=$ predator.

\begin{tabular}{lcccc}
\hline Feeding & Family & Whole thallus & Basal portion & Distal portion \\
\hline $\mathrm{H}$ & Ampithoidae & $0.82( \pm 0.16)$ & $0.92( \pm 0.31)$ & $1.02( \pm 0.61)$ \\
$\mathrm{H}$ & Hyalidae & $24.80( \pm 5.36)$ & $20.57( \pm 3.09)$ & $70.31( \pm 22.26)$ \\
$\mathrm{D}$ & Caprellidae & $13.17( \pm 5.90)$ & $5.03( \pm 1.19)$ & $24.87( \pm 16.29)$ \\
$\mathrm{D}$ & Corophiidae & $2.40( \pm 1.90)$ & $5.70( \pm 2.74)$ & $0.19( \pm 0.13)$ \\
$\mathrm{D}$ & Lysianassidae & $0.08( \pm 0.08)$ & $0.10( \pm 0.10)$ & -- \\
$\mathrm{D}$ & Maeridae & $0.01( \pm 0.01)$ & $0.46( \pm 0.31)$ & - \\
$\mathrm{D}$ & Podoceridae & $0.10( \pm 0.10)$ & $0.02( \pm 0.02)$ & - \\
$\mathrm{D} / \mathrm{P}$ & Amphilochidae & $0.75( \pm 0.45)$ & $0.62( \pm 0.32)$ & $1.37( \pm 0.98)$ \\
$\mathrm{D} / \mathrm{P}$ & Leucothoidae & --- & - \\
$\mathrm{D} / \mathrm{P}$ & Stenothoidae & $0.93( \pm 0.48)$ & $0.02( \pm 0.02)$ & - \\
--- & Eusiridae & $0.08( \pm 0.08)$ & $0.02( \pm 0.02)$ & $0.46( \pm 0.39)$ \\
\hline
\end{tabular}

Natural history aspects, such as behavior and

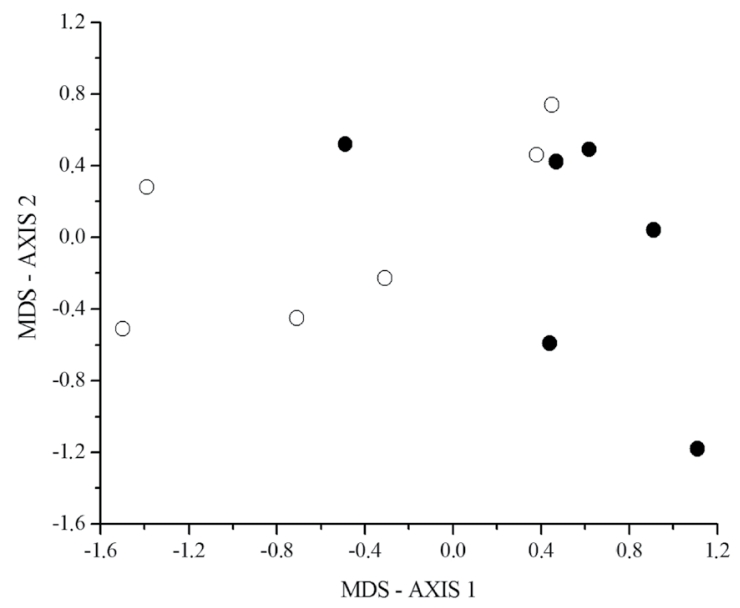

Figure 1. Non-Metric Multidimensional Scaling (nMDS) ordination of the composition of amphipod families associated to distal (solid circles) and basal (open circles) portions of Sargassum stenophyllum. Stress $=0.09$.

space for the establishment of the associated fauna. Also, the holdfast is colonized by sessile organisms, which can function as a second biological substrate for mobile species (Leite et al., 2007). An increase in habitat complexity of a biological substrate (e.g. biomass, surface area) is often related to an increase of fauna diversity (Dean and Connell, 1987), thus it is reasonable to expect a higher variety of microhabitats in the basal portion of Sargassum. Our results concur with this expectation, as we found a higher diversity of the amphipod fauna in the basal portion. Moreover, we did not find differences in variability among species composition from basal and distal portions, so any dissimilarity between these groups is probably due to difference in location (Anderson, 2005). feeding habits, can influence the occurrence of amphipods in macroalgae (Tanaka and Leite, 2003; Jacobucci et al., 2009). The basal portion of Sargassum may be less subject to the action of waves (Rossi et al., 2000; Fraschetti et al., 2006) and because of the proximity to the physical substrate and the weak currents, it may accumulate a larger amount of particles (e.g. sediments and detritus), as observed in kelp forests by Eckman et al. (1989). The detritivore families, Corophiidae, Maeridae, Lysianassidae and Podoceridae, were mainly associated to the Sargassum base, which presents favourable conditions for the accumulation of sediments and detritus. Christie et al. (2007) observed a similar pattern related to the distribution of amphipods associated to Laminaria hyperborea on the coast of Norway. In contrast, Amphilochidae and Stenothoidae did not show clear differences along the Sargassum thallus. These families are represented by amphipods with detritivore and predatory feeding habits (Guerra-García et al., 2014) and, as a result, they may be less dependent on the detritus accumulated at the basal portion of Sargassum. Furthermore, Caprellidae (mainly composed by detritivore species) was denser in the distal portion of Sargassum. It is worth noting that Caprellidae present morphological structures adapted to feed on suspended particles in the water column (Myers and Lowry, 2003), which may explain their higher density in the distal portion, as observed in other macroalgal systems (Hirst, 2007).

Regarding herbivores, the family Hyalidae showed higher density in the distal portion of 
Sargassum. Contrarily to detritivores, this group is less dependent on the accumulation of particles at the Sargassum base. Moreover, the distal portion may represent a less competitive habitat for space, since most groups of amphipods were associated to the basal portion. Interspecific competition can be an important factor structuring the associated fauna community (Edgar, 1990), making the occupation of the distal portion favorable for the success of Hyalidae individuals. Furthermore, younger tissues (at the distal portion) of Sargassum can be more palatable than older tissues (at the basal portion) for herbivorous amphipods (Taylor et al., 2002), which can affect the distribution of Hyalidae along the algal thallus. In contrast, the other herbivorous family, Ampithoidae, did not show any difference regarding its distribution along the Sargassum thallus. Such results concur with the general pattern for herbivorous epifauna along a vertical gradient on macroalgae observed by Hirst (2007), which suggested it may be related to the generalist feeding habit of marine mesoherbivores (Poore et al., 2008), although there are some exceptions (Hay et al., 1990; Poore and Steinberg 1999). Furthermore, we point out that the species of Ampithoidae often build domiciles on the algae using algal pieces and other materials (Conlan, 1982). In this sense, other algal properties related to the building of domiciles (e.g. blade size and quantity) not evaluated in our study may affect the distribution of Ampithoidae along the Sargassum thallus.

Our study showed the composition of amphipod families is influenced by the vertical stratification of Sargassum thallus and, as a result, different parts of the thallus may support distinct assemblages. Such variation may result from the interaction between the natural history of the fauna and the differences in conditions and physical structure along the algal thallus. These findings contribute towards a growing body of studies (e.g. Fraschetti et al., 2006; Christie et al., 2007; Hirst, 2007) that point out the vertical stratification of a macroalgal substrate can add another source of variation to the spatial distribution of associated fauna. In this sense, considering this approach together with the investigation at different spatial scales (e.g. shores, plots and boulders) may be valuable to describe patterns and infer processes regarding the distribution of associated fauna.

\section{ACKNOWLEDGEMENTS}

We thank the Centro de Biologia Marinha, Universidade de São Paulo (CEBIMar - USP) for providing logistic support. We also thank Marília Bueno Fernandes, Edson Vieira Filho and Pedro Joaquim Bergamo for the ideas and contributions in reviewing this article. Finally, we thank the two anonymous reviewers for the helpful comments.

\section{REFERENCES}

Anderson, M.J. 2001. A new method for non-parametric multivariate analysis of variance. Austral Ecology, 26: 3246.

Anderson, M.J. 2005. PERMANOVA: a FORTRAN computer program for permutational multivariate analysis of variance. Department of Statistics, University of Auckland, New Zealand, 24p.

Barnard, J.L. and Karaman, G.S. 1991. The Families and Genera of Marine Gammaridean Amphipoda (Except Marine Gammaroids) (Part 1). Records of the Australian Museum, 13: 1-418.

Castilla, J.C.; Lagos, N.A. and Cerda, M. 2004. Marine ecosystem engineering by the alien ascidian Pyura praeputialis on a mid-intertidal rocky shore. Marine Ecology Progress Series, 268: 119-130.

Christie, H.; Jørgensen, N.M. and Norderhaug, K.M. 2007. Bushy or smooth, high or low; importance of habitat architecture and vertical position for distribution of fauna on kelp. Journal of Sea Research, 58: 198-208.

Conlan, K.E. 1982. Revision of the gammaridean amphipod family Ampithoidae using numerical analytical methods. Canadian Journal of Zoology, 60: 2015-2027.

Coull, B.C. and Wells, J.B.J. 1983. Refuges from fish predation: experiments with phytal meiofauna from the New Zealand rocky intertidal. Ecology, 64: 15991609.

Dean, R.L. and Connell, J.H. 1987. Marine invertebrates in an algal succession. III. Mechanisms linking habitat complexity with diversity. Journal of Experimental Marine Biology and Ecology, 109: 249-273.

Eckman, J.E.; Duggins, D.O. and Sewell, A.T. 1989. Ecology of understory kelp environments. I. Effects of kelps on flow and particle transport near the bottom. Journal of Experimental Marine Biology and Ecology, 129: 173-187.

Edgar, G.J. 1990. Population regulation, population dynamics and competition amongst mobile epifauna associated with seagrass. Journal of Experimental Marine Biology and Ecology, 144: 205-234.

Eston, V.R.; Migotto, A.E.; Oliveira Filho, E.C.; Rodrigues, S.A. and Freitas, J.C. 1986. Vertical distribution of benthic marine organisms on rocky coasts of the Fernando de Noronha Archipelago (Brazil). Boletim do Instituto Oceanográfico, 34: 37-53. 
Fraschetti, S.; Terlizzi, A.; Bevilacqua, S. and Boero, F. 2006. The distribution of hydroids (Cnidaria, Hydrozoa) from micro- to macro-scale: Spatial patterns on habitatforming algae. Journal of Experimental Marine Biology and Ecology, 339: 148-158.

Guerra-García, J.M.; Tierno de Figueroa, J.M.; NavarroBarranco, C.; Ros, M.; Sánchez-Moyano, J.E. and Moreira, J. 2014. Dietary analysis of the marine Amphipoda (Crustacea: Peracarida) from the Iberian Peninsula. Journal of Sea Research, 85: 508-517.

Hacker, S.D. and Steneck, R.T. 1990. Habitat architecture and the abundance and body-size-dependent habitat selection of a phytal amphipod. Ecology, 71: 2269-2285.

Hay, M.E.; Duffy, J.E. and Fenical, W. 1990. Host-plant specialization decreases predation on a marine amphipod: an herbivore in plant's clothing. Ecology, 71: 733-743.

Hirst, A.J. 2007. Vertical stratification of mobile epiphytal arthropod assemblages between the canopy and understorey of subtidal macroalgae. Marine Biology, 150: 427-441.

Jacobucci, G.B.; Tanaka, M.O. and Leite, F.P.P. 2009. Temporal variation of amphipod assemblages associated with Sargassum filipendula (Phaeophyta) and its epiphytes in a subtropical shore. Aquatic Ecology, 43: 1031-1040.

Joly, A.B. 1967. Gêneros de Algas Marinhas da Costa Atlântica Latino-Americana. São Paulo, Editora da Universidade de São Paulo, 461p.

Kelaher, B.P.; Chapman, M.G. and Underwood, A.J. 2001. Spatial patterns of diverse macrofaunal assemblages in coralline turf and their associations with environmental variables. Journal of the Marine Biological Association of the United Kingdom, 81: 917-930.

Koivisto, M.E. and Westerbom, M. 2010. Habitat structure and complexity as determinants of biodiversity in blue mussel on sublittoral rocky shores. Marine Biology, 157: 1463-1474.

Leite, F.P.P.; Tanaka, M.O. and Gebara, R.S. 2007. Structural variation in the brown alga Sargassum cymosum and its effects on associated amphipod assemblages. Brazilian Journal of Biology, 67: 215-221.
McCoy, E.D. and Bell, S.S. 1991. Habitat structure: the evolution and diversification of a complex topic. p. 3-27. In: S.S. Bell, E.D. McCoy and H.R. Mushinsky (eds), Habitat Structure: The Physical Arrangement of Objects in Space. London, Chapman \& Hall.

Myers, A.A. and Lowry, J.K. 2003. A phylogeny and new classification of the Corophiidea Leach, 1814 (Amphipoda). Journal of Crustacean Biology, 23: 443485.

Paula, E.J. 1988. O gênero Sargassum C. Ag. (Phaeophyta Fucales) no litoral do Estado de São Paulo, Brasil. Boletim de Botânica da Universidade de São Paulo, 10: 65-118.

Poore, A.G.B.; Hill, N.A. and Sotka, E.E. 2008. Phylogenetic and geographic variation in host breadth and composition by herbivorous amphipods in the family Ampithoidae. Evolution, 62: 21-38.

Poore, A.G.B. and Steinberg, P.D. 1999. Preferenceperformance relationships and effects of host plant choice in an herbivorous marine amphipod. Ecological Monographs, 69: 443-464.

Rossi, S.; Gili, J.M. and Hughes, R.G. 2000. The effects of exposure to wave action on the distribution and morphology of the epiphytic hydrozoans Clava multicornis and Dynamena pumila. Scientia Marina, 64: 135-140.

Tanaka, M.O. and Leite, F.P.P. 2003. Spatial scaling in the distribution of macrofauna associated with Sargassum stenophyllum (Mertens) Martius: analyses of faunal groups, gammarid life habits, and assemblage structure. Journal of Experimental Marine Biology and Ecology, 293: $1-22$.

Taylor, R.B.; Sotka, E. and Hay, M.E. 2002. Tissue-specific induction of herbivore resistance: seaweed response to amphipod grazing. Oecologia, 132: 68-76.

Wiens, J.A. 1989. Spatial Scaling in Ecology. Functional Ecology, 3: 385-397.

Zamzow, J.P.; Amsler, C.D.; McClintock, J.B. and Baker, B.J. 2010. Habitat choice and predator avoidance by Antarctic amphipods: the roles of algal chemistry and morphology. Marine Ecology Progress Series, 400: 155-163. 